\title{
Research Article \\ Seroprevalence of Hepatitis B Virus in HIV Tested Positive Patients Accessing Treatment in Specialist Hospital Jimeta
}

\author{
Mohammed Bashir ${ }^{1, *},\left(\mathbb{D}\right.$, Halima Ibrahim ${ }^{2}$, Halima $\mathrm{Isa}^{1}$ \\ ${ }^{1}$ Department of Microbiology, School of Life Sciences, Modibbo Adama University of Technology, Yola, Nigeria \\ ${ }^{2}$ Department of Science Laboratory Technology, School of Life Sciences, Modibbo Adama University of Technology, Yola, Nigeria
}

\section{ARTICLE INFO}

Article History

Received 30 September 2020

Accepted 20 March 2021

Keywords

Demographic characteristics rapid diagnostic test seroprevalence coinfection

HBsAg

Jimeta

\begin{abstract}
Background: Human Immunodeficiency Virus (HIV) positive patients are likely to be at risk of other infectious pathogens such as Hepatitis B Virus (HBV). HIV and HBV are blood-borne pathogens and are transmitted via intravenous drug use, sexual contact, or mother to child during pregnancy or birth.

Objective: The present study aimed at determining the seroprevalence of HBV infection among HIV infected patients who are on antiretroviral treatments in Specialist Hospital Jimeta.

Methodology: A hospital-based cross-sectional study was conducted among 246 patients from August 2019 to January 2020 at Jimeta Specialist Hospital, Adamawa state, Nigeria. The presence of HBV was detected using DiaSpot Hepatitis B Surface Antigen (HBsAg) kit, whereas demographic data were obtained using a prestructured questionnaire. In the HBsAg detection test, a small quantity of blood was collected using pasture pipette and centrifuge, and then three drops of the plasma were dropped on the test portion of the strip and left for $15 \mathrm{~min}$; the results were then recorded. Data were analyzed using SPSS for Windows version 25.0 and presented in the form of texts, frequency tables, percentage, and graphs; association was assessed using chi-square test, in which $p<0.05$ is considered statistically significant.

Results: Out of $246 \mathrm{HIV}$ positive individuals screened for the presence of HBsAg, 27 (11.0\%) were positive; 21 (8.6\%) were female and six (2.40\%) were male. Overall, 14 (51.9\%) of the participants are non-educated. The highest prevalence was obtained in the age group of 31-45 years with $16(59.3 \%)$. Moreover, most HIV patients who were HBV positive were single with a prevalence of $15(55.6 \%)$, and $210(38.7 \%)$ have knowledge and understanding of vaccination.

Conclusion and Recommendation: Higher proportions of HIV positive patients are non-educated. Similarly, HIV positive patients who are 30 years or older should always be checked for HBV infection. In particular, HIV positive patients should be screened frequently for the presence of HBsAg during their hospital visit.
\end{abstract}

(c) 2021 Dr. Sulaiman Al Habib Medical Group. Publishing services by Atlantis Press International B.V. This is an open access article distributed under the CC BY-NC 4.0 license (http://creativecommons.org/licenses/by-nc/4.0/).

\section{INTRODUCTION}

Hepatitis B Virus (HBV) increases the risk of liver diseases and when there is coinfection with Human Immunodeficiency Virus (HIV) that will increase the risk of hepatotoxicity because of frequent use of antiretroviral treatments. They share several routes of transmission as both HIV and HBV spread from person to person in semen, blood, or other body fluids. Globally, approximately $90 \%$ of infected patients were infected with $\mathrm{HBV}$, and Hepatitis B Surface Antigen (HBsAg) was detected in the 15\% of HIV positive individuals [1]. They both share certain epidemiological characteristics such as their mode of transmission and the population that is at higher risk of infections. The seroprevalence of HBV in those infected with HIV ranges between 6.3\%

"Corresponding author. Email: mbashir@mautech.edu.ng

Peer review under responsibility of the Dr. Sulaiman Al Habib Medical Group

Data availability statement: All the data supporting the findings of the present study are available within the article; and the citations were properly cited within the text. and 39\% [2]. Furthermore, chronic hepatitis B mortality rate increases because of HIV and it will progress faster to liver cirrhosis and hepatocellular carcinoma. HIV patients who contacted HBV suffered from low HBsAg seroconversion with high levels of HBV DNA [3].

Hepatitis B virus is endemic in Africa and Asia, where most of the infections occur via perinatal transmission, medical and cultural procedures, and close contact with family members. Regardless of HIV infection, the prevalence of HBV is often close to $15 \%$ in both Asia and Africa [4], whereas in Nigeria, several studies have recorded the prevalence of HBsAg to range from $7.5 \%$ to $44.7 \%$ from one locality to another. In Benin City, Nigeria, the prevalence of HBsAg among children is $10.8 \%$ [5]. However, it is expected that the prevalence of $\mathrm{HBV}$ in HIV positive patients will vary from one locality to another. The present study is aimed at determining the seroprevalence of HBV in patients who tested positive for HIV and are accessing treatment at Specialist Hospital, Jimeta. 


\section{MATERIALS AND METHODS}

\subsection{Study Design}

A hospital-based cross-sectional study was conducted among 246 patients from August 2019 to January 2020 at Jimeta Specialist Hospital. The hospital, which has a 474-bed capacity, serves approximately $315-350$ patients daily. It is located in Jimeta (latitude: $9^{\circ} 16^{\prime} 27.00^{\prime \prime} \mathrm{N}$; longitude: $12^{\circ} 26^{\prime} 26.99^{\prime \prime} \mathrm{E}$ ), which has a population of $3,106,585$ [6].

\subsection{Sample Size}

The number of samples collected for the present study was calculated using single mean sample size estimation as described by Naing et al. [7]. The value of $p$ was taken as 0.20 , using the following formula introduced by Daniel [8].

$$
n=\frac{z^{2} p(1-p)}{d^{2}}
$$

where $n$ is the sample size; $z$ denotes statistical for a level of confidence of $95 \%$, which is conventional $(Z=1.96)$; $p$ is the expected prevalence $(p=0.20)$; $d$ is precision $(d=0.05)$. Substituting these values in the above formula, we obtain:

$$
\begin{aligned}
& n=\frac{(1.96)^{2} \times(0.20) \times(1-0.20)}{(0.05)^{2}} \\
& n=245.86
\end{aligned}
$$

Hence, 245.9 samples are required for this study; this number was later approximated to 246 samples.

\subsection{Study Population}

Venous blood samples were collected from 246 patients with HIV who attended Specialist Hospital Jimeta. Written consent was obtained from participants prior to collection of blood samples for the study. The objectives of the study were also explained to the participants.

\subsection{Sample Collection}

Samples were collected by the phlebotomist using standard procedures, in which about $5 \mathrm{~mL}$ of the venous blood sample was collected aseptically by venipuncture and dispensed into a sterile bottle. The sera were separated by centrifugation at room temperature at $300 \mathrm{rpm}$ for $5 \mathrm{~min}$ and taken to the work bench for further processing [9].

\subsection{Determination of $\mathrm{HBsAg}$}

The HBsAg test strip was used for this analysis, and the test was conducted according to the manufacturer's instruction. The strip was open and placed on a dry flat surface. A pasture pipette was used to collect a small quantity of the plasma, and three drops of the plasma were then dropped on the test portion of the strip. The strip was left for $15 \mathrm{~min}$; the result was observed and recorded according to the indication of color band on the test region and the control region.

\subsection{Demographic Data of Participants}

The sociodemographic variables (gender, age, marital status, and educational status) and other associated factors such as knowledge of $\mathrm{HBV}$, history of $\mathrm{HBV}$ vaccination, and vaccination status data were collected using a self-administered prestructured questionnaire after written consent was obtained.

\subsection{Statistical Analysis}

Data were analyzed using SPSS Statistics for Windows, version 23.0 (IBM Corp., Armonk, NY, USA) and presented in the form of texts, frequency tables, percentages, and graphs. Association was assessed using chi-square test, and $p \leq 0.05$ was considered statistically significant [8].

\section{RESULTS}

\subsection{Gender Distribution of HBV in HIV Positive Patients}

The results of the distribution of hepatitis B among HIV positive patients in relation to gender, showed that 27 (11\%) of both male and female participants are hepatitis B positive whereas the remaining 219 (89\%) are negative. A higher prevalence of $\mathrm{HBV}$ and HIV positivity was observed in females $(21 ; 8.6 \%)$ than in males (6; $2.4 \%)$, as depicted in Table 1.

\subsection{Distribution of HBV in HIV Positive Patients with Respect to Educational Status}

Regarding HBV and HIV positivity and educational status of the patients, $92(37.4 \%)$ of patients have secondary school level of education, with one $(3.7 \%)$ positive case; meanwhile, non-educated patients accounted for $51(20.7 \%)$ among HIV positive patients, of whom 14 (51.9\%) were positive (Table 2).

As depicted in Figure 1, most HIV positive patients are aware of $\mathrm{HBV}$, and they are interested in taking the HBV vaccine; however, few of them who were included in this study were vaccinated. Moreover, a large number of HIV positive patients were not tested for HBV. Thus, they were also not vaccinated.

Table 1 Gender distribution of HBV in HIV-positive patients

\begin{tabular}{lccc}
\hline Gender & Positive (\%) & Negative (\%) & Total (\%) \\
\hline Male & $6(2.4)$ & $66(26.9)$ & $72(29.4)$ \\
Female & $21(8.6)$ & $153(62.4)$ & $174(71.0)$ \\
Total & $27(11.0)$ & $219(89.0)$ & $246(100)$ \\
\hline
\end{tabular}

Pearson chi-square $=0.387 ; p=0.538$. 
Table 2 Distribution of HBV in HIV positive patients versus educational status

\begin{tabular}{lccr}
\hline \multirow{2}{*}{ Educational status } & \multicolumn{2}{c}{ HBV test } & \multirow{2}{*}{ Total (\%) } \\
\cline { 2 - 3 } & Positive (\%) & Negative (\%) & \\
\hline Primary & $2(7.4)$ & $56(25.6)$ & $58(23.6)$ \\
Secondary & $1(3.7)$ & $91(41.6)$ & $92(37.4)$ \\
Tertiary & $10(37.0)$ & $35(16.0)$ & $45(18.3)$ \\
Non-educated & $14(51.9)$ & $37(16.9)$ & $51(20.7)$ \\
Total & $27(100)$ & $219(100)$ & $246(100)$ \\
\hline
\end{tabular}

Pearson chi-square $=32.564 ; p=0.000$.

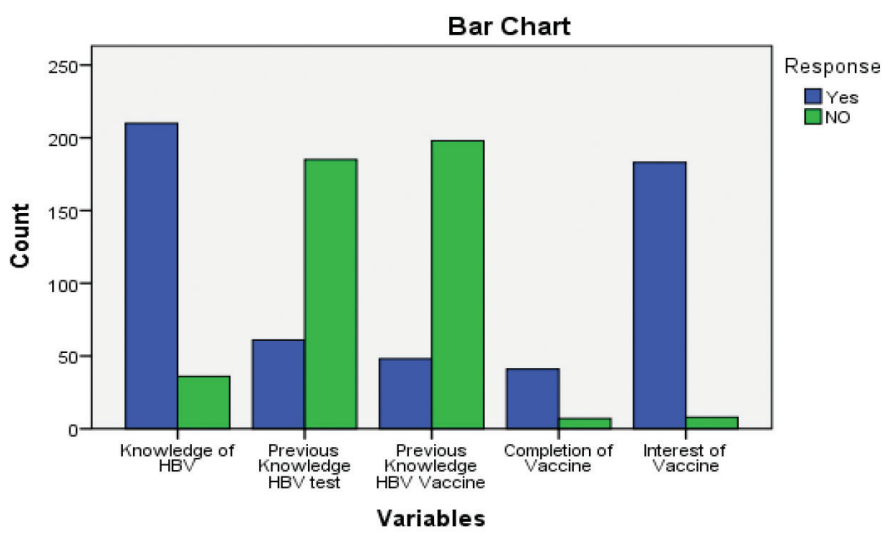

Figure 1 Vaccinated and unvaccinated distribution of hepatitis B virus (HBV) in human immunodeficiency virus (HIV) positive patients.

\subsection{Prevalence of HBV among HIV AIDS Patients based on their Age Group}

Table 3 gives the prevalence distribution of respondents in relation to age categories. The results indicated that the age group of 31-45 years showed the higher number of HBV coinfections with HIV, at $120(48.8 \%)$, of which $16(59.3 \%)$ were positive coinfections, and the least was found in the age group 1-15 years, with a total of nine $(3.7 \%)$ coinfected patients with two $(7.4 \%)$ positive cases.

\subsection{Distribution of HBV in HIV Positive Patients based on Marital Status}

Table 4 depicts the result of the distribution of HBV in HIV patients in relation to marital status. The result of the study revealed that coinfection of HBV is higher in HIV positive patients who are single, with 15 (55.6\%), whereas lowest were found in widows.

\subsection{Distribution of HBV in HIV Positive Patients in Relation to Vaccination Status}

Table 5 shows that $210(85.4 \%)$ of the respondents have knowledge of HBV infection as well as its vaccine. Among 61 (24.8\%) respondents who are aware of the HBV test, 48 (19.5\%) were vaccinated, of whom about $41(16.7 \%)$ have completed their vaccination.
Table 3 Prevalence of HBV among HIV AIDS patients based on age group

\begin{tabular}{lccc}
\hline \multirow{2}{*}{$\begin{array}{l}\text { Age group } \\
\text { (years) }\end{array}$} & \multicolumn{2}{c}{ HBV test } & \\
\cline { 2 - 3 } & Positive (\%) & Negative (\%) & \\
\hline $1-15$ & $2(7.4)$ & $7(3.2)$ & $9(3.7)$ \\
$16-30$ & $3(11.1)$ & $66(30.1)$ & $69(28.0)$ \\
$31-45$ & $16(59.3)$ & $104(47.5)$ & $120(48.8)$ \\
$>45$ & $6(22.2)$ & $42(19.2)$ & $48(19.5)$ \\
Total & $27(100)$ & $219(100)$ & $246(100)$ \\
\hline
\end{tabular}

Pearson chi-square $=5.064 ; p=0.167$. AIDS, acquired immunodeficiency syndrome.

Table 4 Distribution of HBV in HIV positive patients based on marital status

\begin{tabular}{lcrr}
\hline \multirow{2}{*}{ Marital status } & \multicolumn{2}{c}{ HBV test } & \multirow{2}{*}{ Total (\%) } \\
\cline { 2 - 3 } & \multicolumn{1}{c}{ Positive (\%) } & Negative (\%) & \\
\hline Single & $15(55.6)$ & $39(17.8)$ & $54(22.0)$ \\
Married & $8(29.6)$ & $115(52.5)$ & $123(50.0)$ \\
Divorced & $4(14.8)$ & $32(14.6)$ & $36(14.6)$ \\
Widow & $0(0.0)$ & $33(15.1)$ & $33(13.4)$ \\
Total & $27(100)$ & $219(100)$ & $246(100)$ \\
\hline
\end{tabular}

Pearson chi-square $=22.188 ; p=0.000$.

Table 5 Distribution of HBV in HIV positive patients in relation to vaccination status

\begin{tabular}{lrrc}
\hline Variables & Yes (\%) & No (\%) & Total (\%) \\
\hline Knowledge of HBV & $210(85.4)$ & $36(14.6)$ & $246(100)$ \\
Are you aware of HBV test? & $61(24.8)$ & $185(75.2)$ & $246(100)$ \\
Are you vaccinated? & $48(19.5)$ & $198(80.5)$ & $246(100)$ \\
Completion of vaccination & $41(16.7)$ & $205(83.3)$ & $246(100)$ \\
Interest of vaccination & $183(74.4)$ & $63(25.6)$ & $246(100)$ \\
\hline
\end{tabular}

Pearson chi-square $=454.967 ; p=0.000$.

\section{DISCUSSION}

The present study revealed that the overall prevalence of $\mathrm{HBV}$ among HIV positive patients is 27 (11.0\%). This indicates that some HIV positive patients who were receiving antiretroviral therapy in specialist hospital Jimeta are also infected with HBV. A similar prevalence was reported from previous studies carried out in different parts of Nigeria. For example, Hamza et al. [10] observed a prevalence rate of $12.5 \%$ of HBV in HIV positive patients in tertiary hospitals in Northwestern Nigeria. Meanwhile, Otegbayo et al. [11] observed a prevalence of 11.9 in Ibadan; Adewole et al. [12] reported $11.5 \%$ in Abuja, and Lar et al. [13] reported 11.8\% in Jos. Reports of $\mathrm{HBV}$ in HIV positive patients within and outside Nigeria suggested that the situation of coinfection of HBV in HIV positive patients is not affected by environment [14]. Perinatal and early childhood serves as major routes in which $\mathrm{HBV}$ is transmitted in countries with immediate and high HBV endemic areas; the infection rate of $\mathrm{HBV}$ in $\mathrm{HIV}$ positive patients ranges from $10 \%$ to $20 \%$, and this is slower than $10-70 \%$ in observed in Nigeria [15]. However, lower HBV prevalence, that is, $6.2 \%$ and $5.7 \%$ was found among HIV positive patients in Tanzania and Brazil, respectively [14]. 
The highest prevalence of HBV was reported among HIV positive female patients $(8.6 \%)$ compared with males (2.4\%). Similar results were reported among HIV positive patients from a study conducted by Okechukwu et al. [16]. Our results are in line with those reported in another study carried out in Abuja, Nigeria, where large numbers of HIV infected female patients were also found to be infected with HBV [12].

The study observed that most of the HIV positive patients accessing treatments in the study area have knowledge of HBV, but very few of them were tested to check their HBV status. In terms of vaccination, very few of the HIV positive patients have completed their dose of vaccination; this could be a factor that may have increase the prevalence of HBV among HIV positive patients.

In general, as elderly people have lower immunity because of their age, this makes them more susceptible to HBV especially when they are HIV positive. Study respondents within the age group of 31-45 years have the highest percentage distribution of $\mathrm{HBV}$, which could be attributed to their lower immunity as well their lifestyle. A similar study conducted by Okechukwu et al. [16] has observed that HIV patients belonging to the age group of 36-40 years are highly infected with HBV. However, this study suggested that there could be a decrease in HBsAg positivity with age because as HIV patients grow older their immunity also decreases, and they are thus unable to fight off and effectively eliminate most pathogens that get into the body. This could be because many of the infectious pathogens can be flushed out in younger age groups than in older age groups. One of the factors that determine the prevalence and incidence rate of infection is the age of study participants. In the present study, the differences in the prevalence of HBV infection in HIV patients in different age groups indicated that age plays an important role in the prevalence and incidence rate [17].

\section{CONCLUSION}

The findings of this study showed that HIV positive patients are also affected with HBV, and this is a threat to HIV positive patients. This study has also revealed that there is a higher prevalence of $\mathrm{HBV}$ among elderly people than in younger ones, and that this may be a result of the decrease in the level of immunity in older individuals. The rate of infection also suggests the need for a baseline screening for HBV markers in HIV positive patients to reduce and prevent the spread of the disease among HIV patients. Older HIV positive people should be given $\mathrm{HBV}$ vaccination because they are at greater risk of the infection.

\section{CONFLICTS OF INTEREST}

The authors declare they have no conflicts of interest.

\section{AUTHORS' CONTRIBUTION}

All authors contributed to conceptualization and experimental designed of the study. HIs managed literature searches. HI and MB were involved in laboratory experiments and data collection. $\mathrm{HI}$ contributed to the analyses of data generated in the study. The manuscript was written by $\mathrm{MB}$ and HIs, and was reviewed and approved by all authors.

\section{REFERENCES}

[1] Thio CL. Hepatitis B in the human immunodeficiency virusinfected patient: epidemiology, natural history, and treatment. Semin Liver Dis 2003:23;125-36.

[2] Mendes-Corrêa MCJ, Barone AA, de Paula Cavalheiro N, Tengan FM, Guastini C. Prevalence of hepatitis B and C in the sera of patients with HIV infection in São Paulo, Brazil. Rev Inst Med Trop Sao Paulo 2000;42;81-5.

[3] Buseri FI, Seiyaboh E, Jeremiah ZA. Surveying infections among pregnant women in the Niger Delta, Nigeria. J Glob Infect Dis 2010;2;203-11.

[4] Lacombe K, Bottero J, Lemoine M, Boyd A, Girard PM. HIV/ hepatitis B virus co-infection: current challenges and new strategies. J Antimicrob Chemother 2010;65;10-17.

[5] Aliyu B, Manga B, Isa MA. Prevalence of hepatitis B virus among HIV positive patients attending specialist hospital Sokoto, Nigeria. Int J Environ 2013;2;37-44.

[6] National Population Commission. Reports of the final national census result. Abuja, Nigeria: National Population Commission; 2006.

[7] Naing L, Winn T, Rusli BN. Practical issues in calculating the sample size for prevalence studies. Arch Orofacial Sci 2006;1;9-14.

[8] Daniel WW. Biostatistics: a foundation for analysis in the health sciences. 7th ed. New York: John Wiley \& Sons; 1999.

[9] Olokoba AB, Salawu FK, Danburam A, Olokoba LB, Midala JK, Badung LH, et al. Hepatitis B virus infection amongst pregnant women in North-Eastern Nigeria- a call for action. Niger J Clin Pract 2011;14;10-13.

[10] Hamza M, Samaila AA, Yakasai AM, Babashani M, Borodo MM, Habib AG. Prevalence of hepatitis B and C virus infections among HIV-infected patients in a tertiary hospital in North-Western Nigeria. Niger J Basic Clin Sci 2013;10;76-81.

[11] Otegbayo JA, Taiwo BO, Akingbola TS, Odaibo GN, Adedapo KS, Penugonda S, et al. Prevalence of hepatitis B and C seropositivity in a Nigerian cohort of HIV-infected patients. Ann Hepatol 2008;7;152-6.

[12] Adewole OO, Anteyi E, Ajuwon Z, Wada I, Elegba F, Ahmed P, et al. Hepatitis B and $\mathrm{C}$ virus co-infection in Nigerian patients with HIV infection. J Infect Dev Ctries 2009;3;369-75.

[13] Lar PM, Pam VK, Christopher PB, Gwamzhi L, Mawak JD. Prevalence and immune status of HIV/HBV co-infected pregnant women. Afr J Clin Exp Microbiol 2013;14;120-6.

[14] Imade GE, Sagay AS, Ugwu BT, Thacher TD, Ford RW. Seroprevalence of hepatitis B and human immunodeficiency virus infections in pregnant women in Nigeria. J Med Trop 2004;6; $15-21$.

[15] Ejele OA, Nwauche CA, Erhabor O. The prevalence of hepatitis B surface antigenaemia in HIV positive patients in the Niger Delta, Nigeria. Niger J Med 2004;13;175-9.

[16] Okechukwu N, Godwin M, Eugenia O, Desmond E, Patrick O. The seroprevalence of hepatitis B viral infection in HIV tested positive individuals in Owerri, Imo state, Nigeria. J AIDS Clin Res 2014;5;1000273.

[17] Sarkar J, Bandyopadhyay B, Chakrabarty R, Bhattacharya N, Adhikari S, Mondal S, et al. HIV-HBV coinfection among individuals attending the ICTC of a tertiary care hospital in West Bengal, India. ISRN Virol 2013;2013;180150. 